pared with Epilobium ; the stamens of Geranium as compared with Erodiunn. Where the reduction has been unsymmetrical, I suspect it has been due to insect adaptation : as in di-dynamous stamens.

As soon as decussate leaves are secured, then we possess the basis for all ordinary leaf-arrangements.

Dr. Airy alludes to non-existing orders, $\frac{1}{4}, \frac{3}{7}, \frac{4}{9}, \frac{4}{11}$, but in the Jerusalem artichoke the secondary series $\frac{1}{3}, \frac{1}{4}, \frac{2}{7}, \frac{3}{11}, 1_{1}^{5} 8$, occurs frequently, and arises from the breaking up of "tricussate" whorls in an exactly similar manner to the primary series, $\frac{1}{2}, \frac{1}{3}$, $\frac{2}{5}$, \&c., arising out of opposite leaves. On the other hand spirals do not easily, if ever, return to whorls. If any one will notice how curiously the above is executed in the Jerusalem artichoke, he will see that there is evidently some power at work in the plant which, as it were, compels the spiral to form, and to form mathematically, will be convinced, I am sure, that a "twist" is very far from being the cause-there being none whatever in the cases mentioned above : and further, when whorls break up, the leaves are at first quite irregular, but they gradually "right themselves," acquire the proper angular divergence, and the form some member of the spiral arrangements to perfection.

GEORGE HensLow

\section{Flight of Projectiles}

IN reply to the letter of "W. Hope," in NATURE of March 13, I request permission to state that by a simple formula, I meant one that would be easily understood. I dit not intend the word simple to be taken strictly in its mathematical sense.

It is easy for Mr. Hope to employ symbols to represent the initial velocity, angle of elevation, or any other additional particular he may consider necessary for the solution of my problem.

No one possessing the most elementary knowledge of the theory of projectiles can be ignorant of the disturbing elenients to which your correspondent refers, or of others to which he makes no allusion. But these cannot be accurately estimated, and, therefore, must necessarily be neglected in a theoretical investigation. I do not anticipate that they will be found to vitiate the results of theory to the extent Mr. Hope supposes.

In the practical application of the formula for which I have asked, the numerical values of the general symbols, would be the mean of carefully conducted experiments. Thus the trifling variations arising from slight differences in the charge, the amount of fouling, or other causes, would be reduced to a minimum. The variations in the force and direction of the wind would often neutralise each other. For these reasons I cannot agree with Mr. Hope in thinking that the calculation would be either "useless or deluding," on the contrary I believe it wonld be valuable as indicating a mean deflection, about which the experimental deflections would be found to group themselves.

Of one thing I am certain, that it would enable us to bring home to the soldier the great effect of wind in deflecting the bullet, and perhaps it might assist us in dispelling the notion of absurdity which is inseparably associated in his mind with the effurt to hit something by aiming at nothing. In accomplishing this one of the greatest obstacles to the development of skill in rifle-shooting would be removed.

If $\mathrm{Mr}$. Hope will kindly supply me with the formula which have asked for, I can assure him that however lightly he may appreciate the results of his labours, by me, at least, they will be valued, and, I venture to hope, made practically useful. Surely he cannot be in earnest in denouncing all theory which approximates to, but does not exactly accord with practice, as "bastard science, or pedantry." If this dictum be sound, I can only say it would be easy to show that a great deal of the science of our day, gunnery science in particular, is spurious.

General Didion, a high authority, did not consider my problem unworthy of investigation. In the Cours Elementaire De Balistique, he has given a solution which I regret is rather too complicated for my purpose. I should imagine that he would be the last person to expect his theory to afford more than a rough approximation to the results of practice. Hence I conclude that in publishing his calculation for the benefit of the French army, he could have had no conception that his science was "bastard science, or pedantry," and must have been unconscious what a "mischievous unpractical pedant" he was.

School of Musketry, Hythe, March I

$$
\text { ROBERT REID, Sergeant-Major }
$$

Deep Sea Soundings near the Equator

THE following extract from a letter of the captain of the school-ship Mercury, occupied at present in taking deep-sea soundings under the orders of the Board of Commissioners of Public Charities and Correction of New York, has been sent to me by General Bowen, of that Board, who takes much interest in the subject. It will doubtless be gratifying to many of your readers :-

"Our Casella-Miller deep-sea thermometer worked admirably. This beautiful instrument stood the test at a depth of 2,040 fathoms, two miles north of the Equator, in longitude $22^{\circ} \cdot 16^{\prime}$ W., when it indicated a temperature of $35^{\circ} \mathrm{F}$; at $\mathrm{I}, 000$ fathoms $38^{\circ}$; at 400 fathoms $41^{\circ}$; at 300 fathoms $44^{\circ}$; at the surface $81^{\circ} ;$ in the air $80^{\circ}$.

"On our track from the Canary Islands to Rio we found the temperatures at uniform depths to vary about $2^{\circ}$. Our specimens of the bottom from the volcanic region differ in every respect from those obtained in other parts of the ocean."

Ũniversity, New York, March 6

JOHN WM. DRAPER

\section{SURVIVAL OF THE FITTEST}

THE doctrine of the "survival of the fittest " must be strangely understood in some quarters. The American papers report Prof. Agassiz as having expressed himself in this wise at a recent meeting of the Massachusetts State Board of Agriculture, of which he is a member :- "I do not know how animals originated; a brilliant imagination that of Darwin; a very necessary faculty in the scientist. The sense I know too well to misquote him. Hasty generalising of observation is Darwin all over. Natural selection is out of generation. Natural necessity, what is it? Do we find that only the strong beget families? Observe plants at the foot of the White mountains, where are large trees, and so up to the summit, where they are mere shrubs. The weak may and do survive as well as the strong. Ignorance lies at the base of the discussion."

Probably no one naturalist, however eminent, can be expected to know everything, or even all simple things. Can it be possible that Prof. Agassiz supposes (as his argument seems to require) that the dwarf trees in question grow and survive near the top of the mountain, notzvithstanding they are not the fittest, rather than because they are the fittest, for the conditions? And does he conceive the doctrine of natural selection to be founded upon some idea of an abstract fitness, irrespective of the conditions, and not upon the survival of the fittest under and in consequence of the conditions? Surely the argument brought against the doctrine is a good illustration in its favour, only an extremely simple and elementary one.

We never could quite comprehend why Prof. Agassiz should give himself so heartily and persistently to the work of demolishing the doctrine of the derivation of species, in all its forms, considering how large and honourable a part he has himself taken in laying the foundation upon which the modern doctrine has been built. Of these foundations none is stronger than the capital one, generally supposed to be established by him, that the succession of species in time corresponds mainly with that in systematic rank, and is also somehow paralleled in the development of each individual of the higher ranks. So that, in view of his continued but unsuccessful efforts to drive the incoming doctrine out of the land, we counld imagine him addressing his own important discoveries in the words used by Balak to Balaam : - "What hast thou done unto me? I took thee to curse mine enemies, and behoid, thou hast blessed them altogether."

\section{SUB-WEALDEN EXPLORATION.-SECOND} QUARTERLY REPORT

$A$ FRESH survey of the Lower Wealden beds in eastern Sussex by the officers of the Geological Survey Department has quite recently bcen made, The whole dis- 
trict has been recently visited by Messrs. Bristow, Topley, and Drew, and it has been decided to sub-divide the strata hitherto known as the Ashburnham beds into two divisions.

The upper portion, consisting of the mottled clays and shales, will henceforth be called the Fairlight beds, while the lower portion, consisting of shelly limestone intermixed with calcareous shale and gypsum, will retain their old title; unless (as is confidently anticipated) they will be found to represent the Purbeck strata, in which case they will be known as the Sussex Purbecks. In reference to our own immediate object, this recent survey has established beyond doubt that the site of the boring is by far the best that the county of Sussex presents for the purpose.

Quite unexpectedly, on January 28 , at a depth of $13 \mathrm{I}$ feet, a stratified mass of pure white crystalline gypsum (statuary alabaster) was reached. This proved to be over
4 feet in thickness; it was succeeded by to feet of gypseous marl ; then by 3 feet more of alabaster. Afterwards, we passed through I 5 feet of gypsum (more or less impure) varied by seams of crystals of selenite. This discovery has been most opportune. No such accumulation of gypsum was ever met with in Sussex before; and it is some consolation to know that our labour has not been all labour in vain: gypsum is a material which is commercially valuable.

Geologists may therefore inquire, "Where are we now?" The reply is given with caution, and under correction (as the shale seems singularly free from fossils), but as blocks of gypsum are found in the lower strata of the Purbeck sexies, we assume we are near the base of that formaticn, and may with some reasonable contider ce expect to be able to announce before another quarter is over that we are through these problematical beds, and into the Portland series or some subjacent formation.
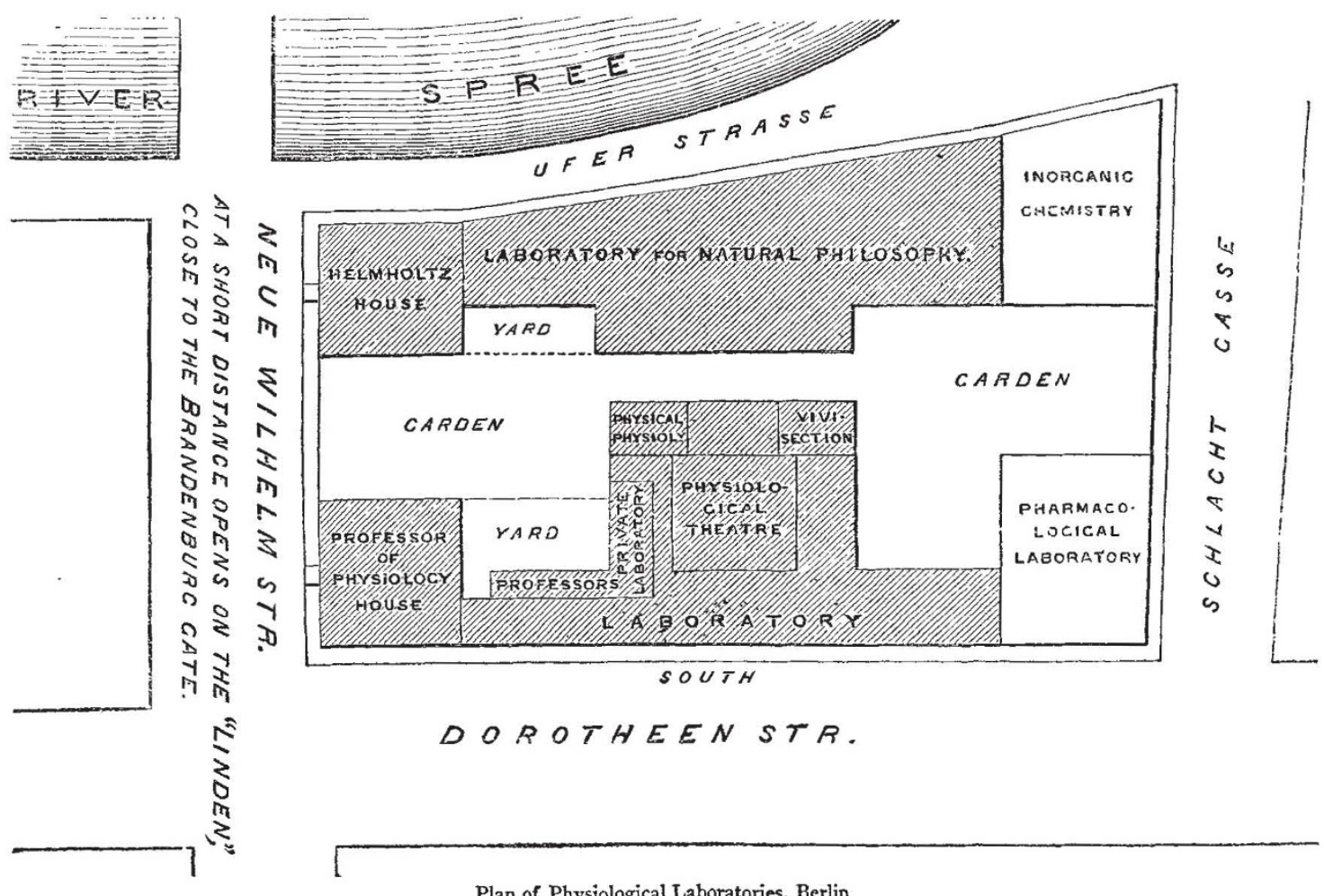

Plan of Physiological Laboratories, Berlin

The question of Finance begins to excite some anxiety in the mind of the treasurer. The amount required for machinery, sheddings, \&c., has more than doubled the original estimate. Coals, tools, and labour, are each dear, and likely to remain so. The difficulty of access will greatly add to the original estimate of expenses. A large portion of our promised aid is given on conditions which render it unavalable at present.

If 2002 . could be raised shortly, it would enable the Finance Committee to authorise the call of the second $1,000 l$; and till this is done we are approaching insolvency. If each existing subscriber would kindly undertake to bring the matter under the notice of some neighbour or friend, we should not only soon raise all we want at present, but be relieved from anxiety for the ultimate prosecution of the enterprise.

We have nothing to do with the cornmercial value of our present or future discoveries; this will be freely given to those who can utilise it. We can only ask for aid from those who will " give, hoping for nothing again,' except scientific discovery.

\section{THE NEW PHYSIOLOGICAL LABORATORIES $A T B E R L I N *$}

THE building of the new laboratory will begin on April $x$. The plans are almost ready, and a most glcricus place it will be, undoubtedly the finest physiological laboratory as well as the largest which was ever areamt of. Besides the large theatre, and every possible accommodation for the lectures, it will contain rooms for collections, for a library, a smaller class-room, apartments for three assistants, lodgings for the servant and his family, \&c. Then, there are five distinct laboratories most scientifically connected; (I) for physiological chemistry; (2) for physical physiology; (3) for vivisections; (4) for

\footnotetext{
* Extract from a letter communicated to us by Dr. Bence Innes.
} 